Engineering Technology Division

FLAW ASSESSMENT GUIDE FOR HIGH-TEMPERATURE

REACTO* COMPONENTS SUBJECT TO

CREEP-FATIGUE IOADING

\author{
R. A Ainsworth \\ Nuclear Electric plc, Berkeley Nuclear Laboratories \\ Berkeley, Glos, GL13 9PB \\ United Kingdom \\ M. B. Ruggles \\ Oak Ridge National Laboratory \\ Oak Ridge, Tennessee 37831-8051 \\ U.S.A \\ Y. Takahashi \\ Central Research Institute of Electric Power Industry \\ Komae Research Laboratory \\ Tokyo 201, Japan
}

Date Published - October 1990

Prepared for the

Electric Power Research Institute

[Research Project 2658-21 (DOE-ERD-86-586)]

As a part of the

Liquid Metal Fast Breeder Reactor EPRI/CRIEPI/NE Joint Study on High-Temperatuie Flaw Assessment Procedure

Prepared by the

OAK RIDGE NATIONAL LABORATORY

Oak Ridge, Tennessee 37831-6285

managed by

MARTIN NIARIETTA ENERGY SYSTEMS, INC.

for the

U.S. DEPARTMENT OF ENERGY

under contract DE-AC05-OR21400 


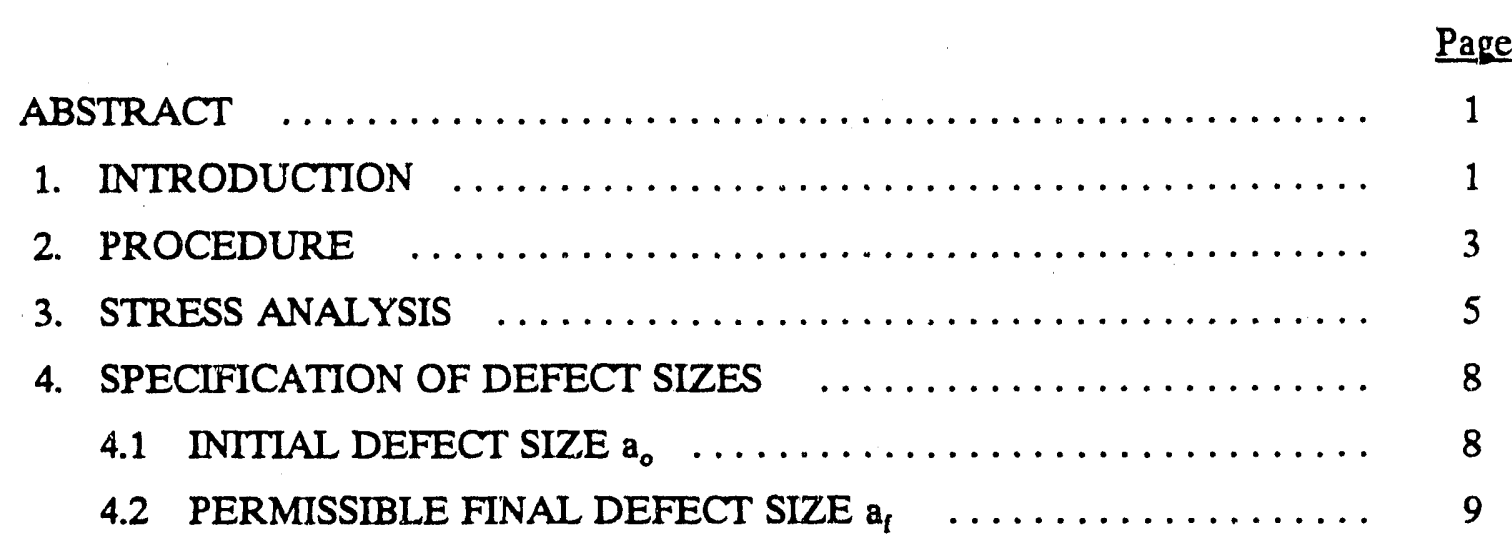

5. CALCULATE EFFECTIVE FATIGUE J-INTEGRAL RANGE $\ldots \ldots \ldots 11$

5.1 ELASTIC RESPONSE $\ldots \ldots \ldots \ldots \ldots \ldots \ldots \ldots \ldots \ldots \ldots \ldots \ldots \ldots \ldots$

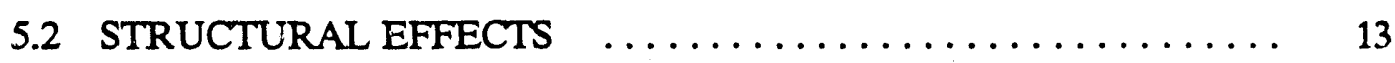

5.3 REPRESENTATION OF CYCLIC DEFORMATION

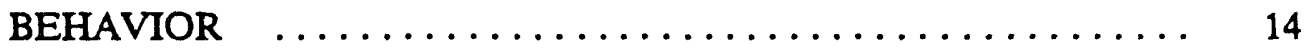

5.4 GE/EPRI METHOD FOR ESTIMATING $\Delta J_{\text {eff }} \ldots \ldots \ldots \ldots \ldots \ldots$.

5.5 REFERENCE STRESS METHOD FOR ESTIMATING $\Delta_{\text {eff }} \ldots \ldots \quad 17$

5.6 LIMITATIONS OF THE APPROACH FOR ESTIMATING $\Delta J_{\text {eff }} \quad \ldots \quad 17$

6. CALCULATE CREEP PARAMETER $C^{*} \ldots \ldots \ldots \ldots \ldots \ldots \ldots \ldots . \ldots . \ldots 20$

6.1 MATERIAL CREEP DEFORMATION BEHAVIOR $\ldots \ldots \ldots \ldots 20$

6.2 GE/EPRI METHOD FOR ESTIMATING $C^{\circ}$ UNDER

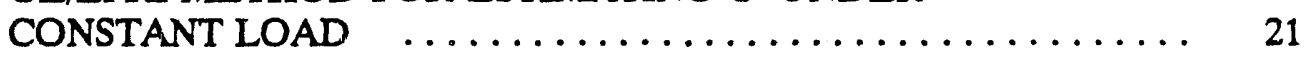

6.3 REFERENCE STRESS METHOD FOR ESTIMATING $C^{\circ}$
UNDER CONSTANT LOAD $\ldots \ldots \ldots \ldots \ldots \ldots \ldots \ldots \ldots \ldots \ldots \ldots$

6.4 ESTIMATING $C^{*}$ UNDER CONSTANT DISPLACEMENT $\ldots \ldots 23$

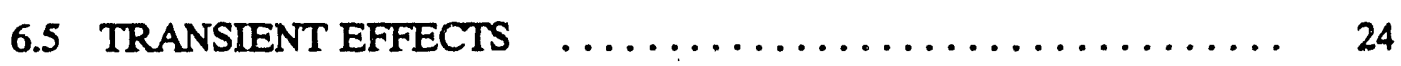

6.6 LIMITATIONS OF THE APPRSACH FOR ESTIMATING C ${ }^{*} \ldots 26$

7. CYCLIC CRACK-GROWTH LAW $\ldots \ldots \ldots \ldots \ldots \ldots \ldots \ldots \ldots$

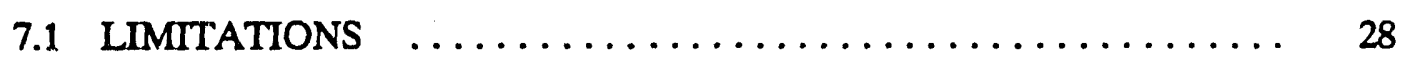

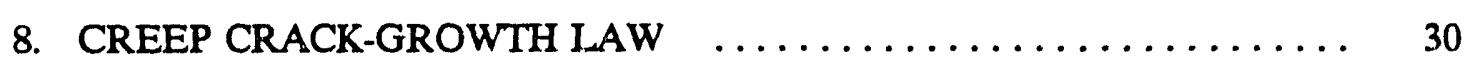

9. INTEGRATION OF GROWTH LAWS $\ldots \ldots \ldots \ldots \ldots \ldots \ldots \ldots \ldots . \ldots \ldots$

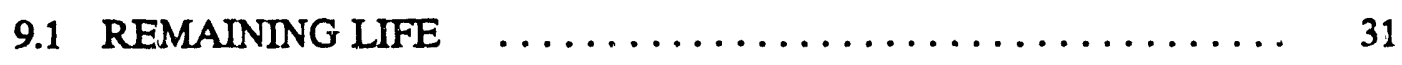

9.2 CRACK EXTENSION $\ldots \ldots \ldots \ldots \ldots \ldots \ldots \ldots \ldots \ldots \ldots \ldots \ldots \ldots \ldots$ 
CONTENTS

Page

10. SENSITTVITY ANALYSIS $\ldots \ldots \ldots \ldots \ldots \ldots \ldots \ldots \ldots \ldots \ldots \ldots \ldots$

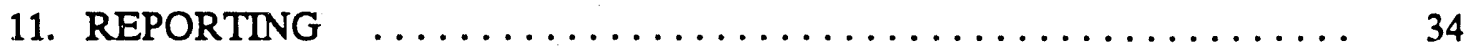

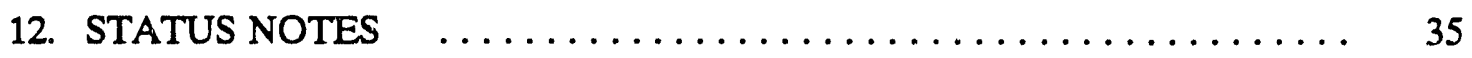

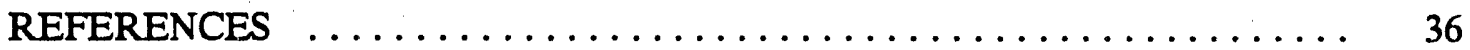




\title{
FLAW ASSESSMENT GUIDE FOR HIGH-TEMPERATURE REACTOR COMPONENTS SUBJECT TO CREEP-FATIGUE LOADING
}

\author{
R. A. Ainsworth \\ M. B. Ruggles ${ }^{\dagger}$ \\ Y. Takahashi ${ }^{\ddagger}$
}

\begin{abstract}
A high-temperature flaw assessment procedure is described. This procedure is a result of a collaborative effort between Electric Power Research Institute in the United States, Central Research Institute of Electric Power Industry in Japan, and Nuclear Electric plc in the United Kingdom. The procedure addresses preexisting defects subject to creepfatigue loading conditions. Laws employed to calculate the crack growth per cycle are defined in terms of fracture mechanics parameters and constants related to the component material. The crack-growth laws can be integrated to calculate the remaining life of a component or to predict the amount of crack extension in a given period. Fatigue and creep crack growth per cycle are calculated separately, and the total crack extension is taken as the simple sum of the two contributions. An interaction between the two propagation modes is accounted for in the material properties in the separate calculations. In producing the procedure, limitations of the approach have been identified.
\end{abstract}

\section{INTRODUCTION}

A joint effort between the Electric Power Research Institute (EPRI) in the United States, the Central Research Institute of Electric Power Industry (CRIEPI) in Japan, and Nuclear Electric plc (NE) in the United Kingdom was started in 1988 to develop hightemperature flaw assessment procedure for reactor components. The first task of the collaboration was to produce a state-of-the-art survey, ${ }^{1}$ and this was followed in 1989 by and

"Nuclear Electric plc, Berkeley Nuclear Laboratories, Berkeley, Glos, GL13 9PB, U.K.

†Oak Ridge National Laboratory, Oak Ridge, Tennessee 37831-8051, U.S.A

*Central Research Institute of Electric Power Industry, Komal Research Laboratory, Tokyo 210, Japan. 
interim progress report, ${ }^{2}$ summarizing a number of experimental results and analytical procedures. This has been updated ${ }^{3}$ to provide a final report on the background work performed within the collaboration.

This document sets out the flaw assessment guide that was the goal of the collaborative effort. It is based on results in the interim ${ }^{2}$ and final reports ${ }^{3}$ and on a hightemperature assessment procedure, ${ }^{4,5}$ known as R5, being developed by NE. It addresses preexisting defects subject to creep-fatigue loading conditions. In producing the procedure, limitations of the approach have been identified in sections dealing with specific calculations required to follow the procedural steps and in a section of status notes.

The crack growth per cycle is calculated using laws that are defined in terms of fracture mechanics parameters and constants related to the material of construction. The fracture mechanics parameters are determined from the operational history, crack size, structural geometry, and the high-temperature material deformation characteristics. The crack-growth laws can be integrated between an initial defect size and a final value to calculate the remaining life of a component, or they can be integrated over a given number of cycles to predict the amount of crack extension in that period.

Cracks can grow in service because of the effects of cyclic changes in operating conditions and because of creep mechanisms where there are long dwell periods between cyclic load changes. In this guide, the cyclic (fatigue) and creep crack growth per cycle are calculated separately, and the total crack extension is taken as the simple sum of the two contributions. However, it is recognized that an interaction can occur between the two propagation modes, and this is accounted for in the material properties used in the separate calculations. 


\section{PROCEDURE}

This section defines the steps to be followed when performing a creep-fatigue crackgrowth assessment. The steps refer to other sections where more guidance is provided concerning the detailed calculations or materials data required to follow the steps. The overall procedure is also shown schematically in the flow chart of Fig. 1.

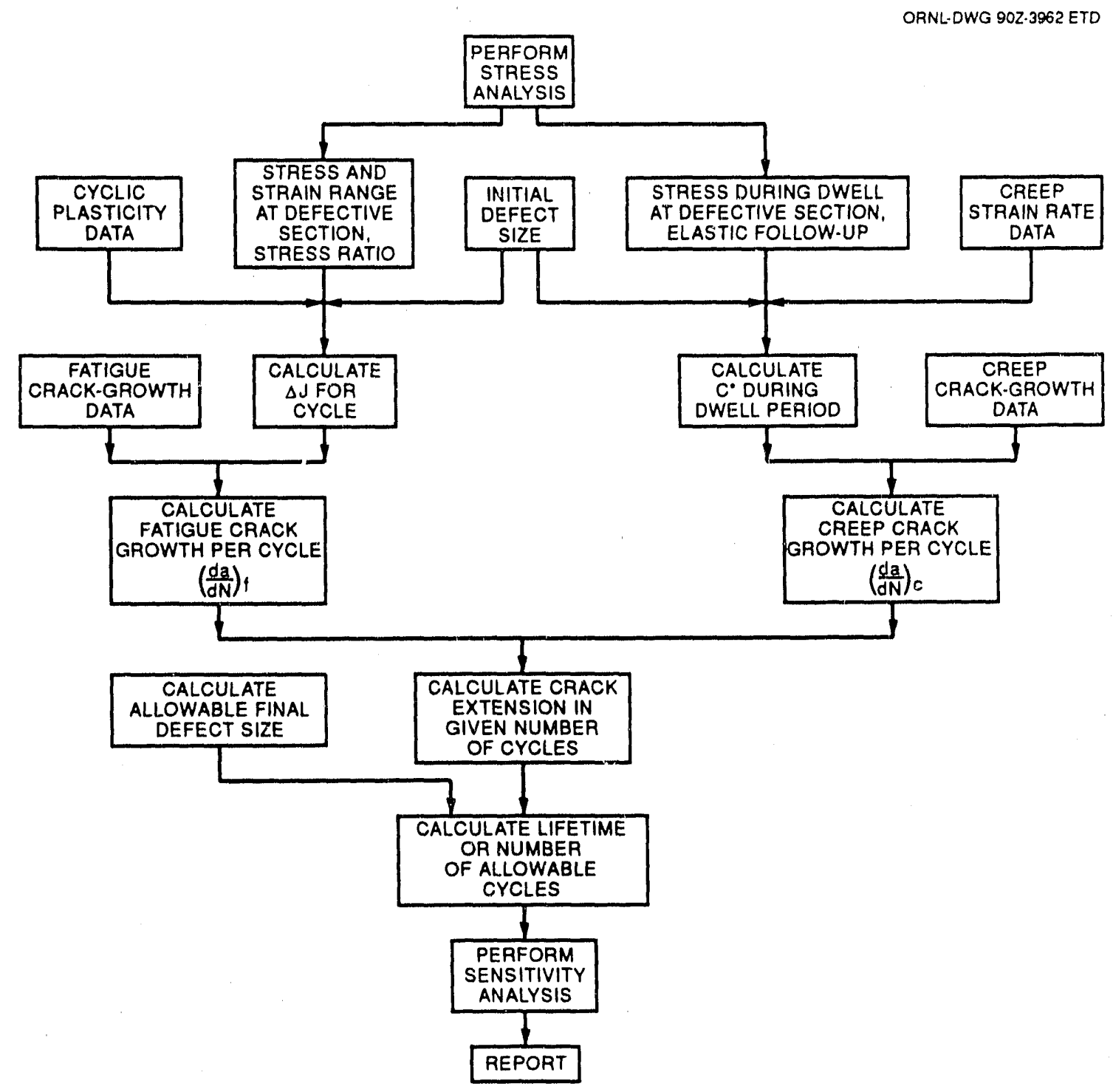

Fig. 1. Flow chart for Assessment Guide. 
Step 1 Determine the temperature and stress histciies at the defective section, making allowance where necessary for the influence of the defect on overall structural response (Sects. 3 and 5.2).

Step 2 Specify the initial defect size $a_{o}$ and estimate if possible at this step the permissible final defect size $a_{\mathrm{f}}$. The latter is the maximum crack size that the structure can safely tolerate under service and overload conditions (Sect. 4).

Step 3 Calculate the effective fatigue J-integral range as a function of crack size, taking due account of the influence of the defect on structural response (Sect. 5).

Step 4 Calculate the creep parameter $C^{*}$ as a function of crack size and time during the dwell period, taking due account of the influence of the defect on structural response and the possible effects of this and cyclic loading on the material deformation behavior (Sect. 6).

Step 5 Experimentally measure or otherwise obtain the cyclic crack-growth rate law (Sect. 7).

Step 6 Experimentally measure or otherwise obtain the creep crack-growth rate law (Sect. 8).

Step 7 Linearly sum the two laws to obtain the total crack growth per cycle and hence obtain either

a. the remaining life by integrating the total crack growth per cycle between crack sizes $a_{o}$ and $a_{f}$ (Sect. 9.1) or

b. the amount of crack extension that occurs from an initial crack size $a_{0}$ in a given number of cycles (Sect. 9.2).

Step 8 Perform a sensitivity analysis with respect to the input data to identify those aspects of the assessment that are life-limiting. Where the calculated remaining life or the calculated crack extension is unacceptable, it may be possible to reappraise the input data, taking due account of their influence on the overall assessment (Sect. 10).

Step 9 Report the results of the assessment and provide information on the analysis methods and materials data used in all aspects of the analysis (Sect. 11). 


\section{STRESS ANALYSIS}

The complete load history experienced by a component is required to properly define the conditions appropriate to the region containing the defect. The history needs to be broken down into well-defined cyclic events or service cycles. Each different service cycle will have an associated cyclic load, a load that operates during the dwell period and a characteristic temperature history. This resolution simplifies the actual loading history so that if is reduced to the application of a well-defined number of different service cycles.

Various forms of stress analysis are available for estimating the stress history from the loading and temperature histories. The most complete would involve inelastic calculations for the defective component performed for several cycles with allowance for increases in crack size due to both cyclic and creep contributions. However, this is impractical for complex components; often assessments can be based on a much simpler stress analysis, such as elastic analysis of the nondefective component.

The:e are several simplified methods of stress analysis at elevated temperature. One of these is the shakedown method ${ }^{5}$ of Voll. 2 of R5; it is applicable to components subject to many cycles where limitation of creep-fatigue damage requires that plastic-strain ranges, plastic strains, and creep strains are all small. Consequently, components reach a steady cyclic state in which behavior of most of the material is essentially elastic, with localized regions experiencing plastic cycling. The shakedown method requires the results of an elastic stress analysis to be available. A residual stress is then added to the elastic stress history to produce a sieady cyclic stress history.

The actual stress cycle is approximated by the shakedown stress cycle $\sigma_{i}^{\text {sh }}(x, t)$ that is a function of position $x$ and time $t$ and is

$$
\sigma_{v}^{s h}(x, t)=\sigma_{v}^{e}(x, t)+p_{v}(x)
$$

where $\sigma_{j}^{e}(x, t)$ is the elastic stress history, and $p_{i j}(x)$ is a time-independent residual stress. This residual stress can be chosen to minimize the value of the stress during the creep dwell period subject to the shakedown stress cycle satisfying the yield criteria. ${ }^{5}$ In practice, minimization is not required because any residual stress which ensures that the yield criteria 
are satisfied can be used. For components subjected to predominantly thermal stress, a convenient choice of residual stress is

$$
p_{v}=\beta \sigma_{U}^{r}
$$

where $\sigma_{y}^{T}$ is the thermal stress at a particular time, usually the time when the thermal stress is a maximum, and $\beta$ is a multiplier. The value of this multiplier is chosen to ensure that the yield criteria are satisfied and to minimize the value of stress during the dwell period. Although this process is ideally performed using a postprocessor to the elastic finite-element code, it can also be done manually by imposing additional temperature loads to the actual loading.

Strictly, achievement of shakedown requires that the yield criteria are satisfied everywhere at all times in the cycle. However, it is known from solutions such as those of Bree, ${ }^{6}$ for example, that shakedown can be exceeded without the occurrence of ratchetting when only limited regions of a cumponent undergo plastic cycling. Therefore, in practice, the strict application of shakedown criteria can be relaxed. It has been suggested ${ }^{5}$ that the shakedown stress cycle can still be used satisfactorily if at least $80 \%$ of any structural section forms a continuous ligament over which strict shakedown is achieved. In cases where regions exist that are not in strict shakedown, the residual stress in Eq. (3.1), or the multiplier $\beta$ in Eq. (3.2), is also chosen to minimize the size of the region that undergoes cyclic plasticity. In those regions where the stress cycle of Eq. (3.1) violates the yield criteria, the Neuber approach in conjunction with a suitable elastic follow-up factor can be used to generate the stress-strain cycle as in other approaches based on elastic analysis.

For the defect assessment procedure described in this document, it is the stress $y_{y}$ at the defective section that is of interest. Where components are subjected to predominantly displacement-controlled or thermal-stress-controlled loading, the presence of a crack can influence the stress history, particularly for deep cracks. This topic is considered further in Sects. 5.2 and 6. 


\section{SPECIFICATION OF DEFECT SIZES}

\subsection{INITIAL DEFECT SIZE $a_{0}$}

The initial defect size $a_{0}$ can be set in a number of different ways, and some examples are

1. the maximum size that can elude detection at the design/manufacturing stage as set by inspection standards;

2. the size of a defect found in service;

3. a size based on experience in fabricating a particular type of component;

4. the maximum size of defect that could be present and yet not have caused failure during a proof test;

5. a defect created at an initially nondefective surface by creep-fatigue mechanisms. This may be estimated, for example, using a modified creep-fatigue endurance that is the number of cycles to produce a defect of a particular size, rather than the number of cycles to cause total failure of a test specimen [(Ref. 4) and Vol. 3 of R5 (Ref. 5)].

In practice, defects discovered by inspection will have an irregular shape. To perform the calculations of Sects. 5 and 6 , it is necessary to characterize such flaws by a circumscribing curve. The American Society of Mechanical Engineers Boiler and Pressure Vessel Code, Section XI (Ref. 7), and the British Standards Institution Published Document 6493 (Ref. 8) contain guidelines for flaw characterization, and these are discussed in some detail in Sect. 9 of the R6 procedure. ${ }^{9}$ Where defects are close together or close to a free surface, these documents also contain criteria for recharacterizing defects by circumscribing curves. The result of this process is that each surface defect is characterized as a semiellipse and each buried flaw as an ellipse.

\subsection{PERMISSIBLE FINAL DEFECT SIZE a}

The maximum permissible defect size $a_{i}$ is the size of defect that can be present and the structure survive service and overload conditions. Where the overload is rapid or occurs at temperatures below the creep range, the value of $a_{1}$ will be controlled by fast fracture or 
short-term ductile failure. One method for predicting the permissible final defect size $\mathrm{a}_{\mathrm{f}}$ is the R6 approach.9 Within this approach, there are several options for deriving the failure assessment diagram and a number of categories of analysis depending on the fracture toughness criterion adopted. The simplest option for the failure assessment curve is option 1 , which is independent of material and geometry. This curve was chosen as an empirical fit to a number of curves derived using the more complex material-dependent option 2 approach, but biased toward the lower bound. ${ }^{10}$ The option 1 curve is close to the option 2 curve for austenitic steels and, therefore, is recommended for use in assessments of fast reactor austenitic components. For such steels, ductile crack growth can lead to significant increases in fracture toughness, and a category 3 analysis that covers ductile tearing is the most appropriate. However, a category 1 analyses that only addresses crack initiation will provide a conservative estimate of $a_{r}$. Note that it may not be possible to perform a fracture mechanics analysis at step 2 when changes in crack aspect ratio occur, as a result of creep-fatigue crack growth. The calculations should then be incorporated at step 7.

In other cases, creep rupture of the remaining ligament ahead of the crack, as calculated by continuum damage mechanics, can control the permissible defect size. The reference stress technique, based on the stresses occurring during the dwell time, is one method that may be used to assess this failure mode. In this approach, ${ }^{11}$ the remaining life at any time $t$ cannot exceed

$$
t_{r}\left[\sigma_{\text {ref }}(t)\right] \text {, }
$$

where $t_{r}$ is the rupture time from uniaxial stress/time-to-rupture data, and $\sigma_{\text {mof }}(t)$ is the reference stress calculated using the crack size $a(t)$ at time $t$ :

$$
\sigma_{r e f}(t)=P \sigma_{Y} / P_{L}\left[\sigma_{p} a(t)\right]
$$

Here, $P_{L}$ is the limit load for the cracked geometry for a yield stress $\sigma_{\boldsymbol{M}}$ and $\boldsymbol{P}$ is the applied load during the dwell period. The total life cannot exceed the current time plus the remaining life $\left(t+t_{r}\right)$, and hence an estimate for the time to failure by continuum damage $t_{C D}$ is

$$
t_{-\infty}=\min _{t}\left\{t+t_{r}\left[\sigma_{r e f}(t)\right]\right\}
$$


In practice, these calculations are performed in conjunction with the crack-growth calculations of Sect. 7 rather than at step 2 in the procedure. Note that for fast reactor structures subjected to low values of mechanical load $\mathbf{P}$, creep rupture is unlikely to be the dominant failure mechanism. 


\section{CALCULATE EFFECTIVE FATIGUE J-INTEGRAL RANGE}

The crack growth per cycle under rapid cyclic loading is well correlated with an effective fatigue $\mathrm{J}$-integral range $\Delta_{\boldsymbol{f}}$ (Sect. 7). For the interpretation of experimental data, direct use of experimental measurements enables $\boldsymbol{N}_{-}$to be determined. However, for application to cumponents, it is necessary to calculate $\Delta J_{d}$ as a function of crack size for defects in the size range $a_{0}$ to $a_{\text {}}$, from the service stresses (Sect. 3 ).

The method of calculating $\Delta_{\text {d }}$ thepends on the magnitude of the service stress range compared to the yield stress and the stress analysis results available. Several methods for

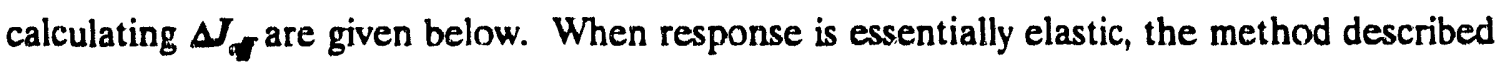
in Sect. 5.1 is appropriate. However, even for elastic response, the defect may influence overall structural behavior, and Sect. 5.2 illustrates the resultant efrect on the calculations. More generally, response is inelastic, and Sects. 5.4 and 5.5 present methods for calculating $\Delta$ using the inelastic materials data tescribed in Sect. 5.3. The methods of Sects. 5.4 and 5.5 have been developed primarily for mechanical loading. The modifications needed to include the effects of thermal stress are given in Sect 5.6.

\subsection{EIASTIC RESPONSE}

The first method described is that of elastic analysis. For this approach to be applicable, the uncracked body stresses must remain elastic, and the crack must be sufficiently small that the remaining ligament can sustain the elastically calculated loads by an essentially elastic response. For deep cracks or when the uncracked-body elastic stresses exceed the yield stress, substantial plasticity can be obtained in the ligament. In such circumstances, the elastic approach is inadequate, and alternative estimates of $\Delta_{\boldsymbol{\alpha}}$ as described in Sects. 5.4 to 5.5 below must be adopted. With the elastic approach, the total stress-intensity factor range is calculated as

$$
\Delta K=K_{\max }-K_{\min },
$$

where $K_{\max }$ and $K_{\min }$ are the values of the stress-intensity factor $K$ at times during the cycle where $\boldsymbol{K}$ has its extreme values. The stress-intensity factor may be calculated from the uncracked-body stresses using a variety of techniques: code solutions, solutions in handbooks, 
and weight function methods (see Ref. 9 for information). Alternatively, finite-element methods allied with various numerical techniques may be used to evaluate $\boldsymbol{K}$

To derive the effective fatigue J-integral range, the *otal stress-intensity factor range must first be modified to account for crack closure, which significantly influences the fatigue crack growth per cycle. Crack closure is influenced by the stress ratio, the maximum stressintensity factor in the cycle (i.e., plasticity), and by the amount of creep strain occurring in dwell periods. ${ }^{12}$ Although methods of calculating crack closure are not well-established, several simplified estunates of closure are defined in terms of only the stress ratio.

Using these estimates, the effective stress-intensity factor range $\Delta K_{-}$is defined as

$$
\Delta K_{\Delta f f}=q_{0} \Delta K
$$

where $q_{0}$ is the total load range for which a crack is judged to be open. This is calculated in terms of the stress ratio $R$ as

$$
R=\boldsymbol{K}_{\min } / \boldsymbol{K}_{\max }
$$

One conservative estimate is given in Ref. 2 and Vol. 5 of R5 (Ref. 5) as

$$
\begin{aligned}
& q_{0}=0.5,-2.5>R ; \\
& q_{0}=1+R / 5,0>R \geq-2.5 ; \\
& q_{0}=1, R>0 .
\end{aligned}
$$

An alternative estimate for $R<0$ that gives similar results to Eq. (5.4) over the practical range of $R$ values is

$$
q_{0}=(1-R)^{-1 / 2}
$$

(see Fig. 16 of Ref. 1).

Having evaluated $\Delta_{-}$the effective J-integral range $\Delta_{d}$ is simply

$$
\Delta J_{\text {sff }}=\left(\Delta \boldsymbol{K}_{\text {sef }}\right)^{2 E^{\prime}}
$$

where $E^{\prime}$ is Young's modulus $E$ in plane stress, and $E^{\prime}=E /\left(1-u^{2}\right)$, where $v$ is Poisson's ratio in plane strain. 


\subsection{STRUCTURAL EFFECTS}

The presence of a defect can influence the overall structural response as calculated by an uncracked-body analysis because the compliance of a section is changed by the presence of a crack. This can result from a combination of the change in elastic compliance and a change in plastic compliance when significant plasticity is induced in the ligament ahead of the crack. These effects can be estimated from known elastic compliance functions, from plastic compliance functions available in handbooks for power-law plastic materials, and by reference stress techniques. In example of the last approach is given in Sect. 4.2 of the background report, ${ }^{3}$ and some results are given below to illustrate the effect of a change in elastic compliance. Note, however, that these structural effects are generally small for shallow cracks.

To illustrate the influence of elastic compliance changes, two examples are given here for displacement-controlled loading. These are taken from Ewing, ${ }^{13}$ who used the line-spring approximation to examine a variety of cases.

The first example is a single-edge-notched (SEN) plate under a fixed rotation loading over a gage length $2 s$. If an uncracked body analysis is used to define the bending moment in terms of the applied rotation, then a stress-intensity factor $K_{\odot}$ is obtained from this bending moment and the stress-intensity factor compliance function for a SEN plate in bending as

given in handbooks. In practice, the stress-intensity factor $K$ is lower than $\boldsymbol{K}_{\phi}$ because of the influence of the defect on the rotational compliance, and

$$
K / K_{0}=\left(1+3 \alpha_{b b} w / S\right)^{-1}
$$

where $\alpha_{\downarrow b}$ is the rotational compliance that is a function of crack depth a and plate width $w$. The second example is a cylinder with an axisymmetric surface defect with a bending stress arising over the cross section (e.g., from an axial temperature gradient in a cylinder with restrained rotation at the crack plane). In this case the stress-intensity factor $\boldsymbol{K}$ is obtained from

$$
K / K_{0}=\left[1+3.856 \alpha_{b b}\left(w / R_{m}\right)^{1 / 2}\right]^{-1},
$$


where $\boldsymbol{R}_{\boldsymbol{m}}$ is the mean radius, and $\boldsymbol{K}_{\boldsymbol{0}}$ is defined using the stress-intensity factor compliance for a SEN plate in bending in conjunction with the bending moment calculated for the uncracked body. The solution is similar to that for the plate with a gage length $s=0.778(R w)^{1 / 2}$. For deep cracks $(a / w>0.4)$, there is significant benefit from including the effect of crack compliance in the stress-intensity factor calculation.

\subsection{REPRESENTATION OF CYCLIC DEFORMATION BEHAVIOR}

Whatever inelastic approach is adopted to derive $\Delta_{\text {en }}$ it is necessary to have a representation of the cyclic stress-strain behavior of the material. The Ramberg-Osgood equation is a convenient description of observed material response and relates the stress range $\Delta \sigma$ to the total strain range $\Delta \varepsilon b y$

$$
\Delta \varepsilon=\Delta \sigma / E+\alpha(\Delta \sigma)^{m},
$$

where $E$ is the elastic modulus, and both $\alpha$ and $\boldsymbol{m}$ are temperature-dependent material constants. Table 1 lists values of the constants for various materials at several temperatures for the saturated cyclic condition.

Table 1. Constants in Ramberg-Osgood approximation for cyclic stress-strain relations

\begin{tabular}{lccccc}
\hline & Material & $\begin{array}{c}\text { Temperature } \\
\left({ }^{\circ} \mathrm{C}\right)\end{array}$ & $\begin{array}{c}E \\
(\mathrm{MPa})\end{array}$ & $\alpha$ & $\mathrm{m}$ \\
\hline CRIEPI & 304 & 200 & 186,000 & $2.46 \times 10^{-12}$ & 3.54 \\
& & 400 & 172,000 & $3.06 \times 10^{-10}$ & 2.70 \\
& & 550 & 157,000 & $3.06 \times 10^{-10}$ & 2.70 \\
& & 650 & 147,000 & $5.08 \times 10^{-14}$ & 4.20 \\
$\mathrm{NE}$ & 321 & 650 & 150,000 & $1.90 \times 10^{-14}$ & 4.40 \\
\hline
\end{tabular}

Equation (5.9) defines the locus of the ranges of stress and strain; it is not the stressstrain loading path. The latter can be obtained directly from test data or can be approximately derived from Eq. (5.9) by assuming that the loading is symmetrical, the stressstrain behavior is independent of cyclic strain range, and that unloading to zero stress level 
is fully elastic. This leads to the loading path $\left(\varepsilon^{\prime}, \sigma\right)$ with the origin defined at the point of zero stress on the tensile-going part of the hysteresis loop being described by

$$
\varepsilon^{\prime}(\sigma)=\sigma / E+\alpha(2 \sigma)^{m},
$$

where $\varepsilon \partial$ is the tensile-going strain. In the case of the type 321 stainless steel tested by the $\mathrm{NE}$, Eq. (5.10) using the constants derived from the ranges of cyclic properties is in good agreement with observed behavior. However, in general the constants $\alpha$ and $m$ required in Eqs. (5.9) and (5.10) need to differ to accurately describe both the locus of the range of stress and strain and the loading path. For the approximate methods described below, it is adequate to describe only the locus of the range of stress and strain by Eq. (5.9). However, if a detailed analysis approach were adopted, then a description of the loading path for a particular strain range would be needed.

\subsection{GE/EPRI METHOD FOR ESTIMATING $\Delta_{\text {eff }}$}

Fully plastic solutions have been calculated for typical specimen geometries and tabulated in nondimensional form by researchers of General Electric (GE) Company under the sponsorship of EPRI. ${ }^{14,15}$ The solutions can also be applied for the simple estimation of the fatigue J-integral range $\Delta_{\rho}$ when the cyclic stress-strain properties are represented by the Ramberg-Osgood equation as in Eq. (5.9). The result is

$$
\Delta J_{f}=\Delta J_{e}+\Delta J_{p},
$$

where $\Delta_{f}$ and $\Delta_{p}$ are contributions of elastic and plastic deformation. These are obtained from

$$
\begin{gathered}
\Delta J_{e}=(\Delta K)^{2 / E^{\prime}}, \\
\Delta J_{p}=\alpha c(a / w) h_{1}(a / w, m)\left(\Delta P \sigma_{d} d P_{0}\right)^{m+1},
\end{gathered}
$$

where $\mathrm{w}$ is section width, $\mathrm{c}$ is a geometrical parameter often equal to the remaining ligament, $\boldsymbol{h}_{\boldsymbol{1}}$ is the nondimensional fully plastic solution for $\boldsymbol{J}$ obtained by interpolation of values in Refs. 14 and 15 for a particular geometry, and $\boldsymbol{P}_{\mathbf{0}}$ is a normalized load that is defined in 
Refs. 14 and 15 and that is proportional to the stress $\sigma_{\sigma}$. Note that the stress $\sigma_{0}$ is not one of the constants in the Ramberg-Osgood Eq. (5.9), and the value of $\sigma_{0}$ does not affect the estimate in Eq. (5.13).

Equation (5.11) does not include any allowance for crack closure, and a reasonable estimate is

$$
\Delta J_{\& f}=q_{0}^{2} \Delta J_{f},
$$

which is consistent with Eq. (5.6) in the elastic limit $\left(\Delta_{p} * \Delta_{e}\right)$ when $R<0$. Equation (5.14) is particularly suitable for strain-controlled cycling conditions. Under conditions of stresscontrolled cycling, strain accumuiation or ratchetting can lead to a large crack-opening displacement and hence reduce the amount of crack closure. In such cases, it is preferable to set $\Delta_{c}=\Delta_{f}$

\subsection{REFERENCE STRESS METHOD FOR ESTIMATING}

The reference stress method has been developed in the United Kingdom to estimate the inelastic deformation of structures from the results of elastic analysis and the limit load. ${ }^{16}$ The estimate of fatigue J-integral range $\Delta_{f}$ is obtained by analogy with reference stress J-estimation methods ${ }^{17}$ as

$$
\Delta J_{f}=\Delta \sigma_{r e f} \Delta \varepsilon_{r e f} R^{\prime}
$$

where

$$
\begin{gathered}
R^{\prime}=\left(\Delta K / \Delta \sigma_{r e f}\right)^{2}, \\
\Delta \sigma_{r e f}=\sigma_{Y} \Delta P / P_{L}\left(a / w, \sigma_{Y}\right) .
\end{gathered}
$$

Here, $\boldsymbol{P}_{\boldsymbol{L}}$ is the limit load for the cracked geometry that can be obtained from tabulated solutions in Ref. 18, and $\Delta \varepsilon_{\text {ng }}$ is the strain range corresponding to $\Delta \sigma_{\text {nd }}$ on the material cyclic stress-strain curve. When the cyclic stress-strain curve is given by Eq. (5.9), 


$$
\Delta \varepsilon_{\text {ref }}=\Delta \sigma_{r q} f E+\alpha\left(\Delta \sigma_{r e f}\right)^{m} \text {. }
$$

In general, Eq. (5.15) does not rely on material behavior being represented by the RambergOsgood relation, and it does not rely on the availability of fully plastic solutions.

Equation (5.15) does not include an allowance for crack closure, but as in Sect. 5.4, it is reasonable to use Eq. (5.14) to define the effective fatigue J-integral range for straincontrolled cycling.

\subsection{LIMITATIONS OF THE APPROACH FOR ESTIMATING $\triangle$ eff}

The approximate methods of Sects. 5.4 and 5.5 rely on solutions that have been developed primarily for mechanical loading. Where the results of the stress analysis (Sect. 3) can be represented by equivalent mechanical loads, such as membrane and bending stress resultants, the approaches can be followed although they may be subject to errors resulting from structural effects as illustrated in Sect. 5.2.

For thermal loading only, $\Delta$, can be estimated simply from the results of an elastic analysis as

$$
\Delta J_{f}=\Delta K^{2} / E^{\prime}
$$

For elastic-thermal stresses well in excess of the yield stress, Eq. (5.19) can significantly overpredict $\Delta_{f}$ A method is given in Ref. 19 for using the results of an elastic-plastic analysis of the uncracked body to obtain an improved estimate. With this method, an effective stressintensity factor range $\Delta K_{1}$ is defined from the uncracked-body, elastic-plastic stress range, normal to the crack plane. An effective stress-intensity factor range $\Delta \boldsymbol{K}_{\mathbf{2}}$ is also defined from the "stress" normal to the crack plane obtained from the range of elastic-plastic, uncrackedbody mechanical strain components as if the material response were linearly elastic. The ranges $\Delta K_{1}$ and $\Delta K_{2}$ are evaluated both for the actual crack size $a$ and also for an effective crack depth:

$$
a_{\text {eff }}=a+\left[\Delta K_{1}(a) / 2 \sigma_{y}\right]^{2} / 2 \pi \beta
$$


where $\beta=1$ and 3 for plane stress and plane strain, respectively. If $a_{d f}$ exceeds the section width $w$, then $a_{a}$ is redefined as $a_{a}=a$. Then the value of $\Delta J_{f}$ for thermal loading is

$$
\Delta J_{f}=\Delta K_{1}(a) \Delta K_{2}(a) / E^{\prime}
$$

or

$$
\Delta J_{f}=\Delta K_{1}\left(a_{e f f}\right) \Delta K_{2}\left(a_{e f o}\right) / E^{\prime}
$$

whichever is the greater.

Where a small constant primary load is superimposed on the cyclic thermal loading, this only affects the stress ratio $R$ of Eq. (5.3) and not $\Delta_{f}$ provided ratchetting does not occur. More generally it is necessary to include plasticity when considering combined mechanical and thermal loading. Such estimates are not discussed in detail here, but Refs. 20 and 21 describe methods for use with the GE/EPRI scheme and the reference stress technique, respectively.

The treatment of crack closure under creep-fatigue loading conditions is complicated in the presence of extensive plasticity. ${ }^{1222}$ In addition, extensive plasticity complicates structural response of the type described in Sect. 5.2 and can lead to structural ratchetting. In tests, closure can be determined from measured load-displacement records, and this confirms the conservatism of Eq. (5.14). Methods for allowing for closure in the presence of extensive plasticity are, however, still under development and are the subject of debate. 


\section{CALCULATE CREEP PARAMETER C*}

During dwell periods in creep-fatigue, crack-growth rates have been successfully correlated with the creep integral $C^{\circ}$. For the interpretation of experimental data, direct use of experimental methods enables $C^{\circ}$ to be determined at times during the dwell and correlated with the corresponding crack-growth rates (Sect. 8). For application to components, it is necessary to calculate $C^{\circ}$ as a function of crack size for defects in the range $a_{0}$ to $a_{f}$ from the service stresses. Several methods for estimating $C^{\circ}$ are described below. The methods described first in Sects. 6.2 and 6.3 are for steady-state response under constant mechanical load. Section 6.4 addresses displacement-controlled loading. Finally Sect. 6.5 describes the transient effects that must be added to the results of Sects. 6.2 and 6.3 to allow for thermal stresses and to allow for the relaxation of initially high crack-tip stresses under mechanical loading.

\subsection{MATERIAL CREEP DEFORMATION BEHAVIOR}

Whatever method is adopted to derive $\boldsymbol{C}^{\circ}$, it is necessary to have a representation of the creep deformation behavior of material in the appropriate cyclically conditioned state. Where the loading is constant during the dwell period, results of constant stress creep tests on cycled material are needed. Creep deformation tests and an equation that fits the data reasonably well are presented in Ref. 3.

Often in creep-fatigue cycles, creep deformation occurs at essentially constant strain during dwell periods. Work within NE on austenitic steels has suggested that stress relaxation under such conditions can be described by a creep equation relating creep strain rate $\dot{\varepsilon}$ to stress $\sigma$.

$$
\dot{\varepsilon}=2 A^{\prime} \sinh \left[\left(\sigma-\sigma_{i}\right) / B^{\prime} \sigma_{0}\right],
$$

where $\sigma_{0}$ is the stress at the start of the dwell, and $A^{\prime}, B^{\prime}$, and $\sigma_{i}$ are material and temperature-dependent constants, with $\sigma_{i}$ being an internal or back stress such that $\dot{\varepsilon}=0$ for $\sigma \leq \sigma_{r}$ Analysis of type 321 steel data at $650^{\circ} \mathrm{C}$ leads to the constants $A^{\prime}=3.6 \times 10^{-7} \mathrm{~h}^{-1}, B^{\prime}=0.005$, and $\sigma_{i}=51 \mathrm{MPa}$. Equation (6.1) enables the stress history, 
and hence the creep strain rate, to be established uncier stress relaxation conditions. Often the experimentally measured stress drop is small, while the creep strain rate reduces considerably. ${ }^{23}$

Although the use of stress relaxation data is preferred for assessments under straincontrolled conditions, such data are not always available. In these cases and for cycles in which creep deformation occurs at essentially constant stress, an alternative is to use forward creep data from constant stress tests. For some materials, stress relaxation can be accurately predicted from forward creep data so that the two options are consistent.

\subsection{GE/EPRI METHOD FOR ESTIMATING C UNDER CONSTANT LOAD}

By analogy with the fully plastic solutions used to evaluate $\Delta_{f}$ in Sect. $5.4, C^{\circ}$ can be estimated by

$$
C^{*}=A c(a / w) h_{1}(a / w, n)\left(P \sigma_{0} / P_{0}\right)^{n+1} \text {, }
$$

where $\boldsymbol{A}$ and $\boldsymbol{n}$ are material constants in the creep law

$$
\dot{\varepsilon}=A \sigma^{n} \text {. }
$$

The value of $\boldsymbol{P}$ is the load level during the dwell period. When this is constant, secondary creep rates can be described by Eq. (6.3), and evaluation of $C^{\circ}$ by Eq. (6.2) is possible. However, creep behavior generally deviates from the steady-state behavior of Eq. (6.3), and particularly for stress relaxation conditions as described in Sect. 6.1, alternative creep laws are appropriate. In these cases, the reference stress method described in Sect. 6.3 below may be used to adapt Eq. (6.2). The result ${ }^{3}$ is

$$
C^{*}=C^{*} \equiv \dot{\varepsilon}_{\text {ref }} / \dot{\varepsilon}_{\text {ref }} \text {. }
$$

Here $C^{\circ}$ is the steady-state value calculated using Eq. (6.2), $\dot{\boldsymbol{\varepsilon}}_{\text {ref }}$ is the steady-state creep strain rate from Eq. (6.3), and $\dot{\varepsilon}_{\text {ref }}$ is the instantaneous creep strain rate from creep data appropriate to the material. These two strain rates are evaluated at a stress level equal to the reference stress of Eq. (6.6) below. 


\subsection{REFERENCE STRESS METHOD FOR ESTIMATING C' UNDER CONSTANT LOAD}

By analogy with the reference stress J-estimation techniques referred to in Sect. 5.5, the value of $C^{*}$ during the dwell period is estimated from

$$
C^{*}=\sigma_{\text {ref }} \dot{\varepsilon}_{r e f} R^{\prime}
$$

The reference stress $\sigma_{\text {of }}$ is defined as

$$
\sigma_{\text {ref }}=P \sigma_{y} / P_{L}\left(a / w, \sigma_{Y}\right)
$$

in a similar manner to Eq. (5.17) with $P$ being the value of load during the dwell period. The length parameter $\boldsymbol{R}^{\prime}$ may be estimated from

$$
R^{\prime}=K^{2} / \sigma_{\text {ref }}^{2}
$$

Equation (6.5) has the same load dependence as Eq. (6.2); but with the choice of $\boldsymbol{R}^{\prime}$ of Eq. (6.7), it is not necessary to have numerical h-functions. This avoids problems of interpolation/extrapolation with such function and enables $C^{*}$ to be calculated for a wider range of cases because solutions for stress-intensity factor and limit load are more widely available than $\mathrm{h}$-functions. The modification introduced in Eq. (6.4) for materials that do not obey power-law creep is based on Eq. (6.5). Validation for this is contained in the work of Riedel $^{24}$ who calculated crack-tip parameters for widespread power-law primary creep and more directly by comparison of Eqs. (6.4) and (6.5) with experimentally and numerically determined values of $C^{*}$ as described in the background report.

\subsection{ESTIMATING C' UNDER CONSTANT DISPLACEMENT}

Under constant displacement conditions, the total displacement rate $\dot{\Delta}$ is zero:

$$
\dot{\Delta}=\dot{\Delta}_{e l}+\dot{\Delta}_{c r}=0
$$


Here $\dot{\Delta}_{e l}$ and $\dot{\Delta}_{c r}$ are the elastic and creep displacement rates, respectively. The elastic displacement rate is proportional to both load-drop rate and crack-growth rate. However, the influence of the change in crack size is not usually of practical importance for component assessments where crack growth is small and is not considered here (further information is contained in Ref. 4 and in the analysis of tests in Sect. 4.1 .3 of the background report. ${ }^{3}$ Consequently,

$$
\dot{\Delta}_{e l}=(\dot{P} / P) \Delta_{e l}
$$

The creep displacement rate is made up of a displacement rate due to the crack $\dot{\Delta}_{c r}^{c}$ and an uncracked-body displacement rate $\hat{\Delta}_{c r}^{\mathrm{cc}}$ :

$$
\dot{\Delta}_{c r}=\dot{\Delta}_{c r}^{c}+\dot{\Delta}_{c r}^{\mu c}
$$

The cracked-body contribution can be determined from reference stress methods or from h3-functions in the GE/EPRI handbook; ${ }^{14}$ the uncracked contribution is straightforward to determine. As in Eq. (6.4), it may be necessary to modify the GE/EPRI scheme when powerlaw creep is not appropriate, particularly because creep behavior under stress relaxation conditions can differ from forward creep response (see Sect. 6.1).

Equations (6.8) to (6.10) enable the load-drop rate to be determined and hence the load as a function of time. The value of $C^{*}$ is then determined using the methods of Sects. 6.2 or 63 with the instantaneous load. With the reference stress method, the load-drop rate can be expressed simply in terms of the change in the reference stress as

$$
\dot{\sigma}_{\text {ref }}=E \dot{\varepsilon}_{\text {ref }} / Z
$$

where $Z$ is the elastic follow-up factor. This is equal to the follow-up factor for the uncracked component plus a contribution for the cracked component reflecting differences 
between elastic and creep compliances. The value $Z=2$ appears to be adequate for general use for the contribution due to the crack; ${ }^{3}$ this corresponds to increasing the elastic follow-up factor for the uncracked component by unity.

It is conservative to use the value of load or reference stress at the start of the dwell in Eqs. (6.2) or (6.5) for estimating $C^{\circ}$ because the amount of stress relaxation is often small. However, changes in $\dot{\varepsilon}_{\text {res }}$ which is the creep strain rate corresponding to $\sigma_{\text {mas }}$ are more significant and need to be considered. For displacement-controlled loadings judged to be strain-controlled, $\dot{\varepsilon}_{\text {ref }}$ can be obtained directly from stress relaxation data.

\subsection{TRANSIENT EFFECTS}

Transient effects occur in two ways for components subjected to cyclic loading in the creep range. The first effect is that the load level at the start of the dwell period can be different in the early cycles to that when a steady cyclic state is reached. If the load level at the start of the dwell periods can be predicted from the stress analysis (Sect. 3), then the methods of Sects. 6.2 or 6.3 can be used for estimating $C^{\circ}$. Where only elastic analysis is avaiiable, redistribution effects can be estimated using Eq. (6.11) and the reference stress at the start of the first cycle as obtained from the elastic analysis. Provided the component is subjected to a large number of cycles, this contribution is small and is not addressed further here.

The second transient effect is adjustment of the crack-tip stress field from the elasticplastic distribution at the end of the cyclic load change to a steady-state creep distribution. Where the loading is displacement-controlled during the dwell period, the reduction in $C^{\circ}$ during the dwell is rapid, and experimental evidence suggests that the approach in Sect. 6.4 adequately describes observed behavior. ${ }^{23}$ Under load-controlled situations or combined thermal/mechanical loading, it is necessary to allow for the transient conditions as described below. However, note that there is some uncertainty about the approach as discussed in Sect. 6.6. 
For relaxation from an initial elastic condition, theoretical and numerical evidence, described in the background report, ${ }^{3}$ suggest that the initial transient fields can be approximated by a term dependent on the initial stress-intensity factor. This leads to

$$
C^{*}=C^{*}[1+1 /(n+1) \tau] \text {, }
$$

or

$$
C^{*}=C^{*} \frac{(1+\tau)^{n+1}}{\left[(1+\tau)^{n+1}-1\right]},
$$

where

$$
\tau=E^{\prime} C^{*}{ }_{\mu}^{t /\left(K_{M}+K_{T}\right)^{2}}
$$

Here, $C^{*}{ }_{\boldsymbol{M}}$ is the value calculated for mechanical loading alone according to the method of Sects. 6.2 or $6.3, K_{M}$ is the stress-intensity factor for the mechanical loading, and $K_{T}$ is the stress-intensity factor for the thermal loading at the start of the dwell. For purely thermal loading $\left(K_{M}=C_{M}^{*}=0\right)$, the time scale of Eq. (6.14) is not determined, but Eqs. (6.12) and (6.13) reduce in the limit $K_{M} \rightarrow 0$ to the common expression

$$
C^{*}=K_{T}^{2} /(n+1) E^{\prime} t
$$

For combined loading, Eqs. (6.12) and (6.13) are not significantly different, but Eq. (6.13) is more convenient for integration. The integration shows that under mechanical loading the contribution of the transient term to crack growth is small provided the accumulated creep strain at the reference stress exceeds the elastic strain at the reference stress. ${ }^{3}$

\subsection{LMMITATIONS OF THE APPROACH FOR ESTIMATING C*}

Although materials creep deformation data have been described in Sect. 6.1, these have been collected either under load control or under stress relaxation. The corresponding creep equations are sometimes different, and therefore there is a need for judgment in 
adopting the more relevant data for service applications. There is a need to develop simplified constitutive equations for behavior intermediate between the two extremes.

Although a method for treating elastic follow-up has been described for displacementcontrolled loading in Sect. 6.4, evaluation of the follow-up factor for cracked components is not simple. Finite-element analyses of simple components are being performed as part of the current collaboration, but further numcrical and experimental evidence is needed to confirm the approach suggested. Also a method for treating elastic follow-up for thermal stress problems is needed.

The approximate methods of Sects. 6.2 and 6.3 rely on solutions that have been developed primarily for mechanical loading. At the start of the dwell period where the stress analysis produces results that can be represented by equivalent mechanical loading, the approaches can be followed. However, in this case, the loading must be treated as all loadcontrolled or all displacement-controlled. In principle the methods of Sects. 6.2-6.4 can be adapted for mixed load and displacement loadings, and this is part of the planned extension to the current program.

The treatment of transient effects by the methods of Sect. 6.5 is not yet well established. Provided the expu ent in the creep crack-growth law is less than unity $[q<1$ in Eq. (8.1) below], then iniegration of crack-growth rates leads to finite results. However, there are problems for $q \geq 1$ with the approaches described because an infinite amount of crack growth is predicted. In practice, the infinite value of $C^{\circ}$ as $t=0$, predicted by Eqs. (6.12) and (6.13), does not occur because of initial plasticity. Also, crack growth can only start after an incubation time rather than at $t=0$. Thus, the integration problems can be overcome by only considering crack growth after some short time, $t_{1}$ (Ref. 25) and by including any effects before $t_{1}$ in the cyclic component of growth. These effects are not fully resolved and are to be addressed in the extension to the current collaboration. The approach described in Sect. 6.5 is expected to be conservative when used in conjunction with crack-growth data derived from load-displacement records, because such data do not reproduce the infinite value of $C^{\circ}$ as $t \rightarrow 0$.

Where thermal stresses at the start of a dwell period can be represented by equivalent mechanical loading, they may be assesred using the methods of Sects. 6.2 and 6.3 (when elastic follow-up is believed to be large) or the method of Sect. 6.4 (when relaxation of the stresses is expected). The method of Sect. 6.5 provides an alternative option in the latter 
case. The two options will produce different results, and the method of Sect. 6.5 is likely to predict the greater amount of crack growth for short times because of the inclusion of the $(1 / t)$ term. When performing an assessment, both options should be calculated as part of the sensitivity analysis (Sect. 10) and the more conservative result adoptèd. 


\section{CYCLIC CRACK-GROWTH LAW}

The crack growth per cycle due to cyclic load changes $(d a / d N)_{f}$ can be represented as

$$
(d a / d N)_{f}=C\left(\Delta J_{e f f}\right)^{2} \text {, }
$$

where $C$ and $\lambda$ are material and temperature-dependent constants. Data are presented in this form in Refs. $1-3$ or in terms of $\Delta K_{d f}$ related to $\Delta J_{d f}$ by Eq. (5.6). Note that, in general, the constants in Eq. (7.1) will be dependent on the previous dwell time and its position in the cycle because growth is expected to occur through creep-damaged material. Representation in terms of an effective J-integral range rather than the total J-integral range is found to reduce the scatter in exferimental data (see Fig. 16 of Ref. 1).

In generating test data, the maximum value of $J$ in a cycle should be insufficient to cause ductile crack extension. The fraction of the cycle for which the crack is open can be obtained experimentally by observing the point on the tension-going part of the specimen load-displacement hysteresis loops at which the specimen compliance changes. The value of $\Delta_{\text {f }}$ can then be obtained from the corresponding area under the load-displacement record as indicated in Ref. 3.

\subsection{LIMITATyNS}

A limitation of the above approach is that any hold-time dependence of the constants in Eq. (7.1) needs to be determined experimentally. Thus, creep-fatigue crack-growth tests need to be performed for a range of hold times and creep crack growth during these hold periods subtracted from the total crack growth. The influence of dwell time is expected to be more marked in materials with low creep ductility (e.g., some austenitic weld metals) than in high-ductility materials (some austenitic base steels). A method for predicting the creep damage and its influence on the cyclic crack growth is clearly desirable. Alternatively, a unified approach for describing the total crack growth per cycle in terms of parameters that can readily be calculated could be developed in the longer term. 


\section{CREEP CRACK-GROWTH LAW}

Although standards for obtaining creep crack-growth data are still in the development stage, methods are reasonably well established (see Ref. 11), and these result in creep crackgrowth rate $\dot{a}$ being described by

$$
\dot{a}=\Lambda C^{* \prime},
$$

where $A$ and $q$ are experimentally determined material constants. $C^{\circ}$ is obtained from experimental load and displacement measurements in a similar manner to obtaining $\Delta_{\boldsymbol{s}}$ Data are presented in this form in Refs. 1-3. The constants $A$ and $q$ are often weakly dependent on hold time and similar in creep-fatigue tests to values obtained for constant loading.

The crack extension per cycle is obtained by integration of Eq. (8.1) as

$$
(d a / d N)_{c}=\int_{0}^{t_{k}} A C^{*} d t
$$




\section{INIEGRATION OF GROWTH LAWS}

The total crack growth per cycle $(d a / d N)$ is simply

$$
d a / d N=(d a / d N)_{f}+(d a / d N)_{c} .
$$

This must be determined for each cycle type. In summing the growth per cycle to obtain the total crack extension or remaining life, account must be taken of the dependence of $\mathrm{da} / \mathrm{dN}$ on crack size $a$ and dwell period $t_{h}$. The dwell period affects $(d a / d N)_{c}$ through the direct integration of the creep crack-growth rate (Sect. 8) and also (da/dN), through the possible dependence of the constants $C$ and $\lambda$ on $t_{k}$ (Sect. 7). Crack size affects $\Delta_{j}$ and $C^{*}$ and hence affects both $(d a / d N)_{f}$ and $(d a / d N)_{e}$

\subsection{REMAINING LIFE}

The number of cycles $N_{g}$ for the crack to grow from the initial size $a_{0}$ to a final size $a_{f}$ is obtained from

$$
a_{f}-a_{0}=\sum_{i=1}^{N_{l}}(d a / d N)_{i},
$$

where $(d a / d N)_{i}$ is evaluated for the crack size and hold time $t_{h}^{i}$ for the ith load cycle. The remaining life $t_{z}$ is then

$$
t_{8}=\sum_{i=1}^{N_{g}} t_{h_{1}}^{i} .
$$

\subsection{CRACK EXTENSION}

The crack extension $a_{e}$ during $N_{0}$ operational cycles is

$$
a_{e}=\sum_{i=1}^{N_{0}}(d a / d N)_{i} .
$$

Note, however, that calculations should not be performed for crack sizes greater than $a_{f}$ 


\section{SENSITTVITY ANALYSIS}

Confidence in determining safe loading conditions is traditionally gained by requiring margins or reserve factors. The procedure described in the previous sections does not contain such factors, although small conservatisms are introduced by some of the approximate approaches. Confidence in an assessment is obtained by the use of lower and upper bound materials data as appropriate and by introducing a measure of conservatism in the analytical calculauions. Additional confidence should then be gained by assessing the sensitivity of the predicted life to variations in the input parameters.

The broad principles of sensitivity analysis for fracture assessments are described in Sect. 12 of R6 Ref. 9 in the context of low-temperature fracture. The sensitivity analysis should consider the effects of different assumptions with regard to loading conditions and material properties. For example, there may be uncertainties in the service loading conditions; the extrapolation of materials data to service conditions; the nature, size, and shape of the flaw; and calculational inputs. Additionally, uncertainties due to the limitations of this procedure as outlined in Sects. 5.6, 6.6, and 7.1 can be examined by means of sensitivity analyses. Confidence is gained in an assessment when it is possible to demonstrate that small changes in input parameters do not dramatically change the remaining life or crack extension; and when realistic variations in the input parameters, whether singly or combined, still lead to a demonstration of margins. 


\section{REPORTING}

When reporting the results of a creep-fatigue crack-growth assessment undertaken according to the procedures of this document, the following information should be presented:

1. loading conditions,

2. materials properties and their source and validity,

3. flaw size and characterization,

4. limit load solution used to define reference stress,

5. stress-intensity factor solution and its source,

6. form of assessment used to define $a_{p}$

7. method used to calculate $\Delta_{-\infty}$

8. method used to calculate $C^{\circ}$,

9. remaining life or crack extension, and

10. results of sensitivity analysis.

Known pessimisms incorporated in the assessment should be listed. All departures from the recommended procedures should be reported. 


\section{STATUS NOTES}

This document represents the current state-of-the-art for creep-fatigue crack-growth assessments. There are, however, limitations and restrictions to the approach, and some of these have been described in Sects. 5.6, 6.6, and 7.1. Other, more general restrictions are listed below.

The procedure as written does not specifically address weldments. Although the methods can be applied to weldments in principle, there is scope for further work to generate materials data for the constituent elements of a weldment and to refine the analysis techniques.

The procedure has been written in terms of mode I loading of a flaw, and shear or mixed modes have not been addressed.

The procedures have been developed for ioad cycles in which the creep deformation in a dwell period occurs as a result of tensile stress fields. Compressive stress fields local to a crack tip would be expected to reduce overall crack-growth rates, but this has not been quantified here. 


\section{REFERENCES}

1. M. B. Ruggles and Y. Takahashi, High Temperature Flaw Assessment Procedure, A Stateof-the-Art Survey, ORNL-6546, Martin Marietta Energy Systems, Inc., Oak Ridge Natl. Lab., May 1989.

2. M. B. Ruggles, Y. Takahashi, and R. A. Ainsworth, High Temperature Flaw Assessment Procedure Interim Report, Martin Marietta Energy Systens, Inc., Oak Ridge Natl. Lab., ORNL/M890, August 1989.

3. M. B. Ruggles, Y. Takahashi, and R. A. Ainsworth, High Temperature Flaw Assessment Procedure Final Report, Martin Marietta Energy Systems, Inc., Oak Ridge Natl. Lab., ORNL/N, 1990.

4. R. A. Ainsworth, "Defect Assessment Procedures at High Temperature," Proc. SMiRT 10 Conference, Anakeim, California, Vol. L, 79-90 (August 1989).

5. R5, An Assessment Procedure for the High Temperature Response of Structures, Volume 2: Analysis and Assessment Methods for Defect-Free Structures, Volume 3: Creep-Fatigue Crack Initiation, Volume 4: Assessment Procedure for Defects Under Steady Loading, Volume 5: Creep-Fatigue Crack Growth, Berkeley Nuclear Laboratories Report, Nuclear Electric plc, United Kingdom, 1990.

6. J. Bree, "Elastic-Plastic Behaviour of Thin Tubes Subjected to Internal Pressure and Intermittent High-Heat Fluxes with Application to Fast-Nuclear-Reactor Fuel Elements," J. Strain Analysis 2, 226 (1967).

7. ASME Boiler and Pressure Vessel Code, "Section XI: Rules for In-Service Inspection of Nuclear Power Plant Components, 1983."

8. British Standards Institution, Guidance on Some Methods for the Derivation of Acceptable Levels for Defects in Fusion Welded Joints, PD6493 (1980).

9. I. Milne, R. A. Ainsworth, A. R. Dowling, and A. T. Stewart, "Assessment of the Integrity of Structures Containing Defects," Int. J. Pres. Ves. Piping 32, 3-104 (1988).

10. I. Milne, R. A. Ainsworth, A. R. Dowling, and A. T. Stewart, "Background to and validation of CEGB Report R/H/R6 - Revision 3," Int. J. Pres. Ves. Piping 32, 105-96 (1988).

11. R. A. Ainsworth et al., "CEGB Assessment Procedure for Defects in Plant Operating in the Creep Range," Fatigue Fract. Eng. Mater. Struct. 10, 115-27 (1987).

12. H. Sehitoglu and W. Sun, "The Significance of Crack Closure Under High Temperature Fatigue Crack Growth with Hold Periods," Eng. Fract. Mech. 33, 371-88 (1989).

13. D. J. F. Ewing, "Stress Intensity Factors for Plates and Shells with Long Part-Through Cracks, as Calculated by a Line-Spring Model," CEGB report TPRD/L/3163/R87, Central Electricity Generating Board, United Kingdom, 1987.

14. V. Kumar, M. D. German, and C. F. Shih, An Engineering Approach to Elastic-Plastic Fracture Analysis, EPRI NP-1931, Electric Power Research Institute, 1981.

15. V. Kumar et al., Advances in Elastic-Plastic Fracture Analysis, EPRI NP-3607, Electric Power Research Institute, 1984. 
16. I. W. Goodall, F. A. Leckie, A. R. S. Ponter, and C. H. A. Townley, "The Development of High Temperature Design Methods Based on Reference Stresses and Bounding Theorems," ASME J. Eng. Matls. Tech. 101, 349-55 (1979).

17. R. A. Ainsworth, "The Assessment of Defects in Structures of Strain Hardening Material," Eng. Fract. Mech. 19, 632-42 (1984).

18. A. G. Miller, "Review of Limit Loads of Structures Containing Defects," Int. I. Pres. Ves. Piping 32, 197-327 (1988).

19. P. J. Budden, Fracture Assessment of Combined Thermal and Mechanical Loads Using Uncracked Body Stress Analysis, CEG13 Report RD/B/6158/R89, Central Electricity Generating Board, United Kingdom, 15189.

20. V. Kumar, B. I. Schumacher, and M. D. German, "Development of a Procedure for Incorporating Secondary Stresses in the Engineering Approach," ASME J. Eng. Matls. Tech 19, 632-42 (1984).

21. R. A. Ainsworth, "The Treatment of Thermal and Residual Stresses in Fracture Assessments," Eng. Fract. Mech. 24, $65-76$ (1986).

22. K. Ohji, "Fracture Mechanics Approach to Creep-Fatigue Crack Growth," Proc. Int. Conf. on Role of Fracture Mechanics in Modern Technology, Fukuoka, Japan, 1986.

23. R. H. Priest, "Crack Initiation and Growth During Creep-Fatigue," Post-Symposium Course of the Second International Symposium on Plasticity, TSU, Japan (1989).

24. H. Riedel, Fracture at High Temperatures, Springer, Berlin, 1986.

25. K. Ohji, K. Ogura, and S. Kubo, "Stress Field and Modified J-Integral near a Crack Tip Under Condition of Confined Creep Deformation" (in Japanese), Zairo 29(320), 467-71 (1980). 

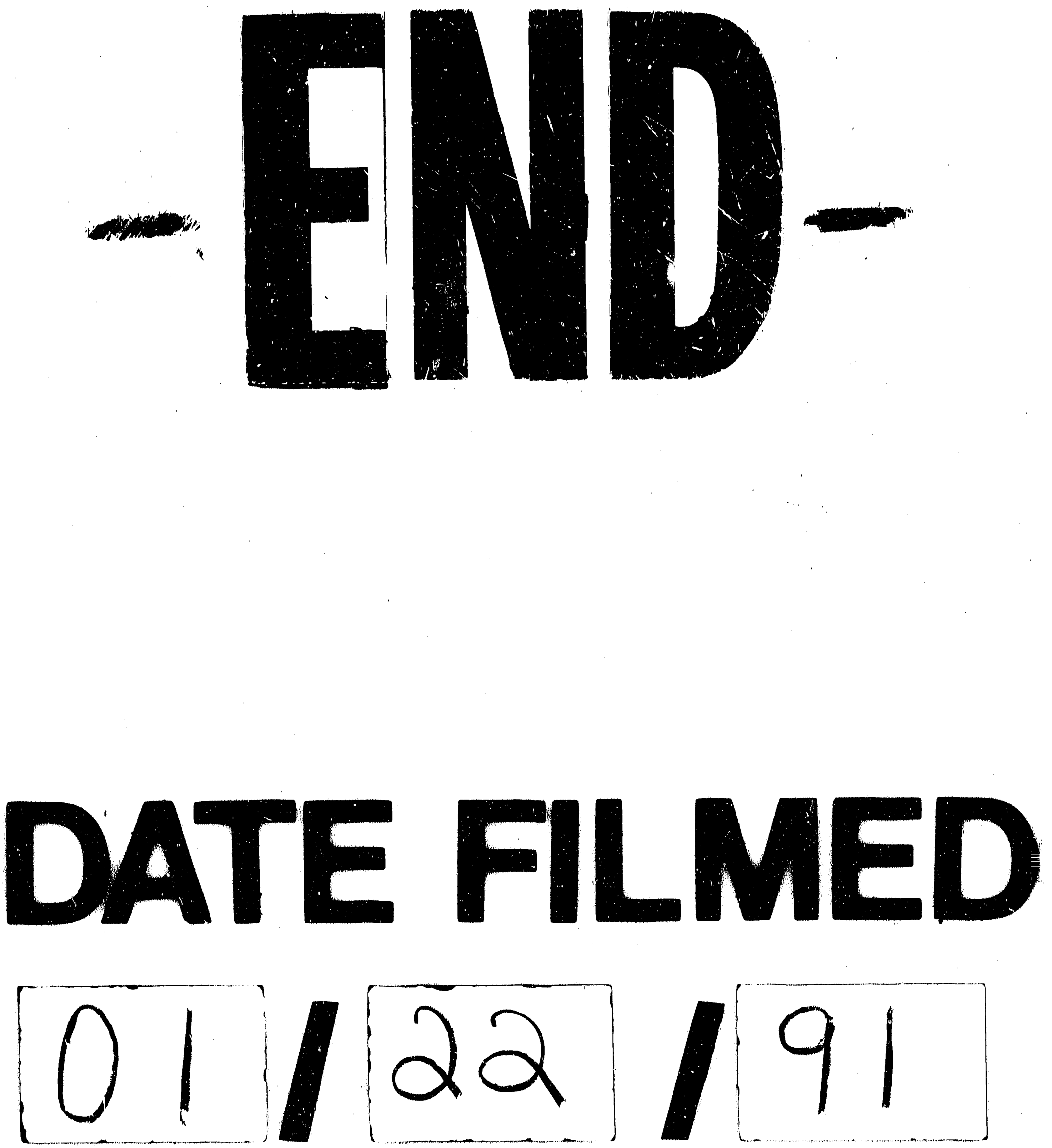
1 